\title{
Reoperation for hemostasis within 24 hours can get a better short-term outcome when indicated after lung cancer surgery
}

\author{
Wei Dai, Xiao-Jun Yang, Xiang Zhuang, Tian-Peng Xie, Ping Xiao, Bin Hu, Xiang Wang, Qiang Li \\ Department of Thoracic Surgery, Sichuan Cancer Hospital \& Institute, Sichuan Cancer Center, School of Medicine, University of Electronic \\ Science and Technology of China, Chengdu 610041, China \\ Contributions: (I) Conception and design: W Dai, Q Li; (II) Administrative support: XJ Yang, X Zhuang, Q Li; (III) Provision of study materials or \\ patients: W Dai, B Hu, X Wang; (IV) Collection and assembly of data: W Dai, B Hu, X Wang; (V) Data analysis and interpretation: W Dai, TP Xie, \\ P Xiao; (VI) Manuscript writing: All authors; (VII) Final approval of manuscript: All authors. \\ Correspondence to: Qiang Li. Department of Thoracic Surgery, Sichuan Cancer Hospital \& Institute, Sichuan Cancer Center, School of Medicine, \\ University of Electronic Science and Technology of China, Chengdu 610041, China. Email: luckydavii@sina.com.
}

\begin{abstract}
Background: Postoperative hemorrhage after lung cancer surgery is a potentially fatal complication. This study aimed to investigate the indications and timing of reoperation for postoperative hemorrhage after lung cancer surgery.

Methods: We identified all patients who underwent lung resection and mediastinal lymph node dissection for lung cancer between October 2001 and September 2015 at Sichuan Cancer Hospital, identifying 57 who had undergone reoperation for hemostasis. The records of these 57 patients were reviewed and analyzed.

Results: The most common postoperative hemorrhage site was the separation surface of the original pleural adhesions $(29.8 \%)$. The median time interval between the initial operation and reoperation was 12 hours (range, 2-432 hours), and most patients (77.2\%) underwent reoperation within 24 hours. The overall morbidity and mortality rates of reoperation were $50.9 \%$ and $5.3 \%$, respectively. The morbidity rates of the early reoperation group ( $\leq 24$ hours) and the late reoperation group were $43.2 \%$ and $77.0 \%$, respectively, which were significantly different $(\mathrm{P}=0.033)$. The mortality rates of the early reoperation group and the late reoperation group were 0 and $23.1 \%$, respectively, which were also significantly different $(\mathrm{P}=0.010)$.

Conclusions: Once indications of reoperation for postoperative hemorrhage after lung cancer surgery are identified, reoperation within 24 hours after the initial operation can get a better short-term outcome.
\end{abstract}

Keywords: Lung cancer surgery; postoperative complications; postoperative hemorrhage; hemothorax; reoperation

Submitted Dec 19, 2016. Accepted for publication May 14, 2017.

doi: $10.21037 /$ jtd.2017.09.85

View this article at: http://dx.doi.org/10.21037/jtd.2017.09.85

\section{Introduction}

Complications following lung resection occur in approximately $24.1-53 \%$ of patients (1-5). Most complications are respiratory, including atelectasis and lung infection, and usually can be managed with conservative treatment (6). More severe complications requiring reoperation, such as postoperative hemorrhage, chylothorax, and bronchopleural fistula, are infrequent, occurring in approximately $3-4.6 \%$ of patients $(5,7-9)$, but the mortality from these events is very high (approximately 5.1-17.8\%) (7,9,10).
Postoperative hemorrhage requiring reoperation after lung resection occurs in approximately $2.6 \%$ of patients (11), and it is the most common indication for reoperation after lung resection, accounting for approximately $26.6-73.3 \%$ of cases $(7,9,10,12)$. There have been few published studies on this topic, and most studies on this subject were published in German or Russian (8,12-14). In addition, most of these studies were outdated and had very small sample sizes (7-9,11-14). To the best of our knowledge, the indications and timing of reoperation for this complication, especially after lung cancer surgery, are not well elucidated in the 
literature. In the present study, we analyzed the clinical data of 57 patients to investigate the indications and timing of reoperation for postoperative hemorrhage after lung cancer surgery.

\section{Methods}

The study was approved by the Ethics Committee of Sichuan Cancer Hospital. Informed consent was also obtained from the patients before surgery.

\section{Patient selection}

We searched the database of the Department of Thoracic Surgery at Sichuan Cancer Hospital, identifying 3,910 patients who underwent lung resection and mediastinal lymph node dissection for lung cancer between October 2001 and September 2015. There were 2,750 patients operated upon by open surgery and 1,160 patients by videoassisted thoracoscopic surgery (VATS). Fifty-seven (1.5\%) patients requiring reoperation for postoperative hemorrhage were eligible for this study. Exclusion criteria included exploratory thoracotomy, biopsy, incomplete resection and those with incomplete data. The medical records of all 57 patients were retrospectively reviewed, with emphasis on extracting information on the causes, indications, timing, and short-term outcomes of reoperation.

\section{Treatment and evaluation}

All patients underwent inhalation anesthesia and intravenous anesthesia through a double-lumen endotracheal tube. Standard posterolateral thoracotomy was employed for open surgery and three-port or four-port technique was used for VATS. After surgery, two chest tubes were used for upper lobectomy and one chest tube for the rest lung resections. Generally, the chest tubes were removed when the residual lungs were re-expanded adequately and the chest drainage was less than $200 \mathrm{~mL}$ per day. Caprini risk assessment model was used to identify venous thromboembolism high-risk patients, and low-molecular-weight heparin was selectively applied in these patients after making a comprehensive assessment of bleeding and thrombosis risk.

The pathologic stages of the patients were based on the seventh edition of the TNM classification for lung cancer, and patients diagnosed and treated before 2009 were re-staged according to the revised TNM staging system (15). Tumors were typed according to the World Health
Organization histologic typing of lung tumors (16). Early reoperation was defined as any chest reoperation performed to control postoperative bleeding within 24 hours after the initial operation. Late reoperation was defined as a reoperation performed more than 24 hours after the initial operation. Among the 57 patients, 44 were classified to the early reoperation group, while 13 were the late reoperation group. Mortality was defined as the number of deaths occurring within 30 days of surgery or within the initial postoperative hospitalization if this exceeded 30 days. Overall mortality rates were defined as the cumulative percentage of deaths with the change of time to reoperation. Overall morbidity rates were defined as the cumulative percentage of patients who have complications with the change of time to reoperation.

\section{Statistical analysis}

Statistical analysis was performed by the SPSS software (version 17.0). Continuous variables are presented as mean \pm standard deviation (SD) and the comparisons between groups use the Student's $t$-test. Categorical variables are presented as proportions and the comparisons between groups use chi-square test. A two-sided $\mathrm{P}$ value of $<0.05$ was considered to be statistically significant.

\section{Results}

\section{Preoperative characteristics}

The preoperative characteristics of these 57 patients classified to the early reoperation group and the late reoperation group are presented in Table 1 . There were 47 males $(82.5 \%)$ and 10 females. The average age of the patients was $60.3 \pm 8.9$ years (range, $38-77$ years). Thirtyseven patients $(64.9 \%)$ had a history of smoking and 2 patients $(3.5 \%)$ had a history of pulmonary tuberculosis. In addition, 2 patients (3.5\%) underwent induction therapy, 2 patients $(3.5 \%)$ received preoperative anticoagulant therapy, and no patients underwent previous thoracic surgery. There were no statistically significant differences $(\mathrm{P}>0.05)$ between the early reoperation group and the late reoperation group regarding preoperative characteristics as shown in Table 1.

\section{Operative characteristics}

The operative characteristics of the 57 patients are shown in Table 2. The average operative time was $149.7 \pm 44.7$ minutes 
Table 1 Preoperative characteristics of all 57 patients

\begin{tabular}{|c|c|c|c|}
\hline Variables & $\begin{array}{c}\text { Early } \\
\text { reoperation } \\
\text { group }(n=44)\end{array}$ & $\begin{array}{l}\text { Late } \\
\text { reoperation } \\
\text { group }(n=13)\end{array}$ & $\mathrm{P}$ value \\
\hline $\begin{array}{l}\text { Age (years, mean } \pm \\
\text { SD) }\end{array}$ & $59.8 \pm 8.9$ & $61.9 \pm 9.0$ & $0.475^{a}$ \\
\hline Male, n (\%) & 34 (77.3) & 13 (100.0) & $0.139^{b}$ \\
\hline $\begin{array}{l}\text { Smoking history, } \mathrm{n} \\
(\%)\end{array}$ & $27(61.4)$ & $10(76.9)$ & $0.483^{b}$ \\
\hline $\begin{array}{l}\text { Induction therapy, } \mathrm{n} \\
(\%)\end{array}$ & $1(2.3)$ & $1(7.7)$ & $0.407^{b}$ \\
\hline $\begin{array}{l}\text { Pulmonary } \\
\text { tuberculosis history, } \\
\mathrm{n}(\%)\end{array}$ & $2(4.5)$ & $0(0)$ & $1.000^{b}$ \\
\hline $\begin{array}{l}\text { Preoperative } \\
\text { anticoagulant } \\
\text { therapy, n (\%) }\end{array}$ & $2(4.5)$ & $0(0)$ & $1.000^{b}$ \\
\hline
\end{tabular}

(range, 60-250 minutes). Most patients (84.2\%) had pleural adhesions. Upper lobe resection was the most common type of lung resections (61.4\%). The surgical approaches were VATS in 11 cases and open surgery in 46 cases (80.7\%). Adenocarcinoma was the most common histologic type (54.4\%). Stage I lung cancer accounted for $42.1 \%$ of cases. There were no statistically significant differences ( $>0.05)$ between the early reoperation group and the late reoperation group regarding operative characteristics as shown in Table 2.

\section{Postoperative characteristics}

A detailed list of all 57 patients' postoperative characteristics after the initial operation is presented in Table 3. Most patients $(66.7 \%)$ had clinical manifestations of shock, such as hypotension, tachycardia and low or no urine output. Postoperative chest radiographs or chest computed tomography (CT) scans were obtained of 53 patients, and the vast majority $(84.9 \%)$ had opacity on chest radiographs or heterogeneous high-attenuation pleural fluid on chest CT scans. The median rate of postoperative chest bloody fluid drainage (CBFD) was $94 \mathrm{~mL} / \mathrm{h}$ (range, 0-600 mL/h). Fourteen cases (24.6\%) had CBFD exceeding $200 \mathrm{~mL} / \mathrm{h}$ persisting for 3 hours. The median time interval between the initial operation and reoperation was 12 hours (range, 2-432 hours), and most patients (77.2\%) underwent reoperation within 24 hours after the initial operation.

\section{Origin of postoperative bleeding}

A detailed list of all the origins of postoperative bleeding is presented in Table 4. The most frequent origin of postoperative bleeding was the area where pleural adhesions were separated $(29.8 \%)$, followed by the region of lymph node dissection (19.3\%) and hemothorax with an unknown origin $(19.3 \%)$. Other sites of postoperative bleeding included bronchial artery (10.5\%), intercostal blood vessel $(7.0 \%)$, chest wall invasion resection surface $(7.0 \%)$, pulmonary artery branch $(3.5 \%)$, pulmonary artery trunk $(1.8 \%)$ and pulmonary resection surface $(1.8 \%)$.

\section{Short-term outcomes after reoperation}

After reoperation, bleeding ceased in 56 patients. One patient underwent a third operation for bleeding 30 days after the second operation. The overall morbidity and mortality rates of reoperation were $50.9 \%$ and $5.3 \%$, respectively, as shown in Figure 1. The morbidities of the early reoperation group and the late reoperation group were $43.2 \%$ and $77.0 \%$, respectively, and the difference was significant $(\mathrm{P}=0.033)$. The mortalities of the early reoperation group and the late reoperation group were 0 and $23.1 \%$, respectively, and the difference was also significant $(\mathrm{P}=0.010)$.

\section{Discussion}

Hemorrhage after lung cancer surgery is a relatively rare but serious postoperative complication. In our study, the rate of reoperation for hemorrhage was $1.5 \%$, and the mortality of reoperation was $5.3 \%$, which was consistent with the previous reports $(7,10)$. It was reported that postoperative hemorrhage after lung resection was the most common indication for reoperation $(9,10,13)$.

Lung cancer surgery involves both lung resection and mediastinal lymph node dissection, creating more potential hemorrhage sites when compared with other types of lung surgery. In our study, most patients $(84.2 \%)$ had pleural adhesions, and the most common site of postoperative hemorrhage was the area where pleural adhesions were separated, followed by small vessels in the wound surface after mediastinal lymph node dissection. Intraoperative temporary electrocoagulation hemostasis of the above two sites was often associated with exposure difficulty; however, 
Table 2 Operative characteristics of all 57 patients

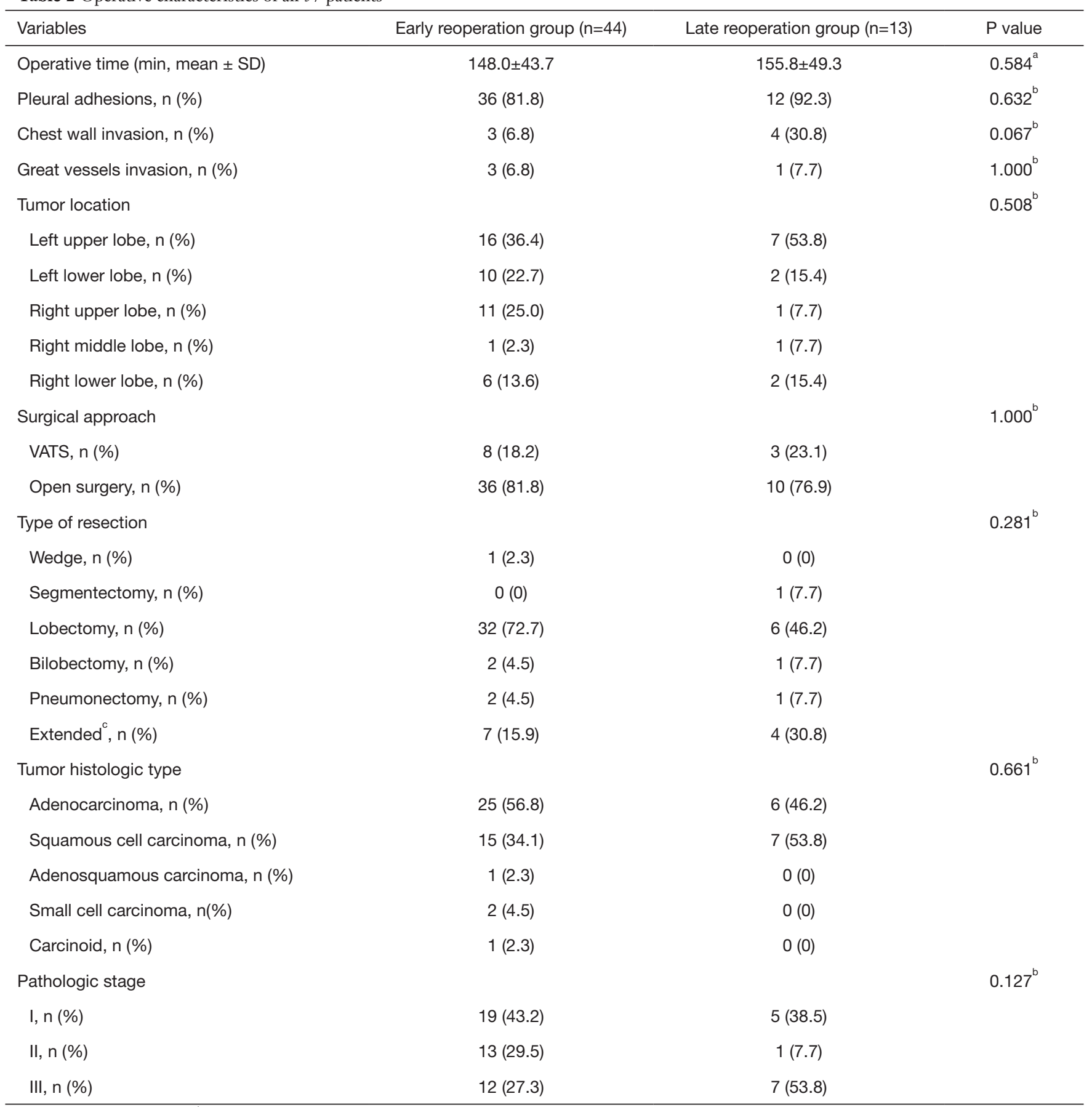

a , by student's $t$-test; ${ }^{b}$, by chi-square test; ${ }^{c}$, lobectomy plus wedge resection, chest wall resection, major vascular resection or bronchoplasty. VATS, video-assisted thoracoscopic surgery.

shedding of the eschar due to postoperative intrathoracic negative pressure formed again may cause re-hemorrhage or wound errhysis. This may be one of the reasons. Other bleeding sites of reoperation, such as bronchial artery, intercostal blood vessel, pulmonary artery branch and pulmonary artery trunk, were mainly considered to result from technical issues during surgery, including single electrocoagulation hemostasis, simple hemostasis by 
Table 3 Postoperative characteristics after the initial operation

\begin{tabular}{lcc}
\hline Characteristic & $\begin{array}{c}\text { Number of } \\
\text { patients }\end{array}$ & Percentage \\
\hline Shock signs and symptoms & 38 & $66.7(38 / 57)$ \\
Blood hemoglobin $\leq 90 \mathrm{~g} / \mathrm{L}$ & 22 & $40.7(22 / 54)$ \\
$\begin{array}{l}\text { Opacity on chest radiograph or } \\
\text { heterogeneous high-attenuation }\end{array}$ & 45 & $84.9(45 / 53)$ \\
pleural fluid on chest CT scan & & \\
CBFD >500 mL/h for 1 hour & 3 & $5.3(3 / 57)$ \\
CBFD >200 mL/h for 3 hours & 14 & $24.6(14 / 57)$ \\
CBFD >1,000 mL within 12 hours & 16 & $28.1(16 / 57)$ \\
CBFD >2,000 mL within 24 hours & 4 & $7.0(4 / 57)$ \\
Time to reoperation, in hours & & \\
$\leq 12$ & 29 & $50.9(29 / 57)$ \\
$\leq 24$ & 44 & $77.2(44 / 57)$ \\
$\leq 72$ & 54 & $94.7(54 / 57)$ \\
\hline
\end{tabular}

Table 4 Origin of postoperative bleeding for reoperation

\begin{tabular}{lcc}
\hline Origin of bleeding & $\begin{array}{c}\text { Number of } \\
\text { patients }(\mathrm{n}=57)\end{array}$ & Percentage \\
\hline Pulmonary resection surface & 1 & 1.8 \\
Pulmonary artery trunk & 1 & 1.8 \\
Pulmonary artery branch & 2 & 3.5 \\
Chest wall invasion resection & 4 & 7.0 \\
surface & 4 & 7.0 \\
Intercostal blood vessel & 6 & 10.5 \\
Bronchial artery & 11 & 19.3 \\
Hemothorax-unknown origin & 11 & 19.3 \\
Lymph node dissection surface & 17 & 29.8 \\
Pleural adhesion separation & & \\
surface & & \\
\hline
\end{tabular}

compression, or insecure vessel ligation. In recent years, due to the progress of modern surgical instruments, such as the linear cut stapler, reports of great vessel bleeding or lung resection surface bleeding had gradually declined $(7,9,10)$. In our group, there were only 2 cases of great vessel bleeding and lung resection surface bleeding.

Reoperation after lung cancer surgery brings greater trauma to patients and increases the risk of severe complications. Therefore, it is very important to decide correctly whether and when to carry out reoperation. If the indications and timing of reoperation for hemostasis are not well controlled, the optimal time to handle the problem may be missed, threatening the patient's life. The diagnosis of postoperative intrathoracic hemorrhage is usually based on the patient's clinical manifestations, chest drainage, and related auxiliary examinations, such as blood tests, chest radiographs or CT scans $(7,9,14)$. However, the indications of reoperation for hemostasis after lung surgery are controversial, and have not been systematically summarized. Traditional indications of reoperation for hemostasis may overemphasize the significance of postoperative chest drainage. The common indication is having bloody fluid drainage from the chest exceeding $200 \mathrm{~mL} / \mathrm{h}$ persisting for 3 hours in some areas and for 4 to 6 hours in other areas (17). However, in our study, few patients $(24.6 \%)$ met the above criteria, and most patients presented as chronic bleeding, with CBFD less than 200 $\mathrm{mL} / \mathrm{h}$, persisting for longer than 3 hours. Compared with chest drainage, we think that imaging examinations, i.e., chest radiographs or chest CT scans, may be more exact and important in judging postoperative bleeding, especially in chronic bleeding, because they are less affected by other factors. In our study, $84.9 \%$ of patients had opacities of the operated hemithorax on chest radiographs or had heterogeneous high-attenuation pleural fluid on chest CT scans. Based on our study and a review of the literature, the indications of reoperation for hemostasis after lung cancer surgery are recommended as follows: (I) the patient has clinical manifestations of hemorrhagic shock failing conservative management, such as blood transfusion; (II) the patient experiences CBFD exceeding $500 \mathrm{~mL} / \mathrm{h}$ for 1 hour, exceeding $200 \mathrm{~mL} / \mathrm{h}$ for 3 hours, exceeding $1,000 \mathrm{~mL}$ within 12 hours, or exceeding $2,000 \mathrm{~mL}$ within 24 hours $(14,17)$; (III) the chest radiograph shows an opacity of more than $20 \%$ of the operated hemithorax volume, or chest CT scan shows heterogeneous highattenuation pleural fluid, which may finally form a pseudotumor (18-20).

It is a clinical consensus that the earlier the reoperation is carried out when indicated, the better the outcomes can get. The question is when is the optimal timing of reoperation. The definition of early reoperation has not been well established. Sirbu et al. (9) defined early reoperation as chest re-exploration performed within 72 hours after the initial operation, and Foroulis et al. (7) defined it to be within 4 weeks. However, we think these times may be too long 


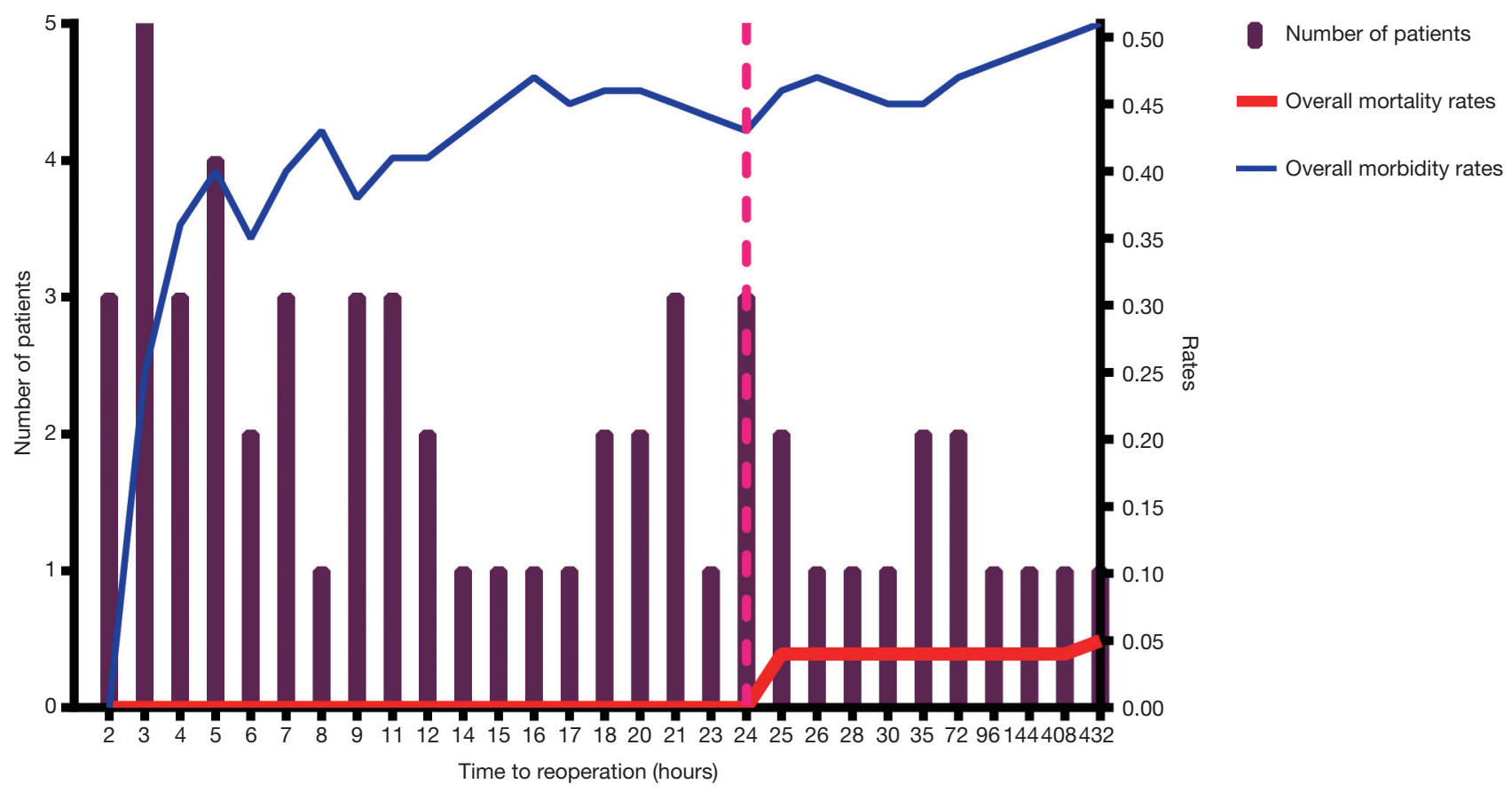

Figure 1 Number of patients, overall morbidity rates and overall mortality rates based on time to reoperation. The left part of this chart was a frequency distribution histogram, showing the number of patients on the left $y$-axis and time to reoperation on the $x$-axis. The right $y$-axis represented a cumulative percentage with the change of time to reoperation on the $\mathrm{x}$-axis. The time to reoperation of 24 hours on the $\mathrm{x}$-axis was an obvious inflection point where the morbidity and mortality rates both increased.

for postoperative bleeding, which is usually an emergency and early complication. According to our study, $77.2 \%$ of patients underwent reoperation within 24 hours after the initial operation and the risk of morbidity and mortality after reoperation significantly increased when the time to reoperation exceeded 24 hours as shown in Figure 1. Therefore, we define early reoperation for postoperative bleeding performed within 24 hours after the initial operation, as defined in the study of Yang et al. (10). In our study, both the morbidity rates and mortality rates of the early reoperation group were lower than those of the late reoperation group, and the differences were statistically significant $(\mathrm{P}<0.05)$. Therefore, we conclude that the optimal timing of reoperation for hemostasis is within 24 hours when indicated.

The main limitations of this study are its retrospective nature, single-center design, and the small number of included patients. The main strength of this study is that it is a special study of postoperative hemorrhage after lung cancer surgery, with emphasis on investigating the indications and timing of reoperation for hemostasis, which has not been well elucidated in the literature as far as we are aware. Future prospective studies are required to further confirm our results.

In conclusion, postoperative hemorrhage after lung cancer surgery requiring reoperation is an infrequent but potentially fatal complication. Once indications are identified, reoperation for hemostasis after lung cancer surgery would preferably be carried out within 24 hours to avoid serious consequences.

\section{Acknowledgements}

Funding: This work was supported by a grant from the Key Research Project of Science and Technology Department of Sichuan Province (2017SZ0013 to Qiang Li).

\section{Footnote}

Conflicts of Interest: The authors have no conflicts of interest to declare.

Ethical Statement: All patients gave informed consent. The Ethics Committee of Sichuan Cancer Hospital approved this study. 


\section{References}

1. Allen MS, Darling GE, Pechet TT, et al. Morbidity and mortality of major pulmonary resections in patients with early-stage lung cancer: initial results of the randomized, prospective ACOSOG Z0030 trial. Ann Thorac Surg 2006;81:1013-9; discussion 1019-20.

2. Duque JL, Ramos G, Castrodeza J, et al. Early complications in surgical treatment of lung cancer: a prospective, multicenter study. Grupo Cooperativo de Carcinoma Broncogenico de la Sociedad Espanola de Neumologia y Cirugia Toracica. Ann Thorac Surg 1997;63:944-50.

3. Harpole DH Jr, DeCamp MM Jr, Daley J, et al. Prognostic models of thirty-day mortality and morbidity after major pulmonary resection. J Thorac Cardiovasc Surg 1999;117:969-79.

4. Pei G, Zhou S, Han Y, et al. Risk factors for postoperative complications after lung resection for non-small cell lung cancer in elderly patients at a single institution in China. J Thorac Dis 2014;6:1230-8.

5. Van't Westeinde SC, Horeweg N, De Leyn P, et al. Complications following lung surgery in the DutchBelgian randomized lung cancer screening trial. Eur J Cardiothorac Surg 2012;42:420-9.

6. Faber P, Piccione W Jr. Complications of surgery in the lung cancer patient. In: Pass HI, Mitchell JB, Johnson $\mathrm{DH}$, et al. editors. Lung cancer: principles and practice. Philadelphia: Lippincott Raven Publishers, 1996: 615-32.

7. Foroulis CN, Kleontas A, Karatzopoulos A, et al. Early reoperation performed for the management of complications in patients undergoing general thoracic surgical procedures. J Thorac Dis 2014;6 Suppl 1:S21-31.

8. Palffy G, Forrai I, Csekeo A, et al. Analysis of reoperations after 10,000 lung resections. Zentralbl Chir 1984;109:72-80.

9. Sirbu H, Busch T, Aleksic I, et al. Chest re-exploration for complications after lung surgery. Thorac Cardiovasc Surg
1999;47:73-6.

10. Yang $\mathrm{Y}$, Gao W, Zhao H, et al. Risk factors and consequences of perioperative reoperation in patients undergoing pulmonary resection surgery. Surgery 2016;159:591-601.

11. Peterffy A, Henze A. Haemorrhagic complications during pulmonary resection. A retrospective review of 1428 resections with 113 haemorrhagic episodes. Scand J Thorac Cardiovasc Surg 1983;17:283-7.

12. Plaksin SA, Petrov ME. Optimization of surgical strategy in complications after thoracic operations demanding recurrent surgical interventions. Vestn Khir Im I I Grek 2014;173:54-9.

13. Neef H, Erbe HJ. Bleeding complications after lung surgery (author's transl). Zentralbl Chir 1977;102:664-9.

14. Thetter O, Habekost M, Izbicki JR. Rethoracotomy after lung resection. Langenbecks Arch Chir Suppl Kongressbd 1991:161-5.

15. Detterbeck FC, Boffa DJ, Tanoue LT. The new lung cancer staging system. Chest 2009;136:260-71.

16. The World Health Organization histological typing of lung tumours. Second edition. Am J Clin Pathol 1982;77:123-36.

17. Shields TW, LoCicero J, Reed CE, et al. General thoracic surgery. 7th edition. Philadelphia: Lippincott Williams \& Wilkins, 2009.

18. Bommart S, Berthet JP, Durand G, et al. Imaging of postoperative complications following surgery for lung cancer. Diagn Interv Imaging 2017;98:11-20.

19. Kim EA, Lee KS, Shim YM, et al. Radiographic and CT findings in complications following pulmonary resection. Radiographics 2002;22:67-86.

20. Rotman JA, Plodkowski AJ, Hayes SA, et al. Postoperative complications after thoracic surgery for lung cancer. Clin Imaging 2015;39:735-49.
Cite this article as: Dai W, Yang XJ, Zhuang X, Xie TP, Xiao P, Hu B, Wang X, Li Q. Reoperation for hemostasis within 24 hours can get a better short-term outcome when indicated after lung cancer surgery. J Thorac Dis 2017;9(10):3677-3683. doi:10.21037/jtd.2017.09.85 